\title{
Study of The Role of Lesson Plan On Job Performance of Secondary School Teachers in Sari City in The 2016-17
}

\author{
Mohammad Yazdani Peraei ${ }^{1}$, Zohre Esmaeili $^{2}$, Mohammad Jamalzade $^{3}$ \\ ${ }^{1}$ Degree of M.A. in Curriculum- Payame Noor University- Department of Tehran-Pardis. \\ ${ }^{2}$ Ph.D., Payame Noor University, faculty member. \\ ${ }^{3}$ Ph.D., Payame Noor University, faculty member.
}

\begin{tabular}{l} 
ARTICLE INFO \\
\hline Keywords: \\
Lesson Plan \\
Job Performance \\
Teacher \\
Secondary School
\end{tabular}

\section{Background and Problem Statement:}

Teaching without a pre - designed application of blind work and design without performing a task is fruitless, which will adorn the pages of paper. The skilled and experienced teacher, before training, thinks about his class 's educational activities and tries to take advantage of the facilities involved in the process of learning and learning; but the inexperienced and inexperienced teacher starts teaching the results and the process of educational activities and the use of facilities; and the difference between the two lies in the same point. The curriculum is a teacher " $\mathrm{s}$ guide and a systematic and organized framework for educational events.

The course plan should be set in such a way that even a novice can perform its educational activities in the classroom in general. A course of training may include a week, a month, a term or a school

* Corresponding Author E-Mail Address: mamadmkt569@gmail.com 
year. The curriculum regulator must divide the educational content of a period based on purpose, results, and time assigned, into various phases and meetings. in order to achieve the goals, set, programs and training activities have to be customized to the ability of the learners and the desired time (Shabani, 2012; 247-248).

The lesson plan is the plan and plan that the Teacher provides for each of its classes, or specifies the required details to train one or more subjects on a subject (Miller and Miller, 2014).

The teacher " s manual is the teacher " s guide, because on one side the teacher is confident, especially the naïve teachers, and on the other hand, the material needs to be taught at a certain time and status, thereby becoming easier to control the class by the teacher.

It might be better for each teacher to adjust course in his own way. Although some teachers claim that they do not need to write the program and are planning lessons in their minds, it should not be forgotten that experienced teachers are constantly planning, and the summary of the lesson that is well written gives more confidence than anything else to the novice teacher (Farajollahi, 2014, 182 - 183).

One of the undeniable ways to improve the quality of education is school planning and education. The curriculum is a process to set appropriate goals and identify issues, requirements, facilities and constraints that are available to achieve those goals (Taghipoor, 2000).

In a good lesson plan, at least some elements and structures such as curriculum matter, general purpose of the subject, objective and behavioral intentions, educational assessment, educational activities, teaching methods, teaching methods, teaching methods, practice of teaching, practice of learning, and complementary activities outside the classroom should be (Niaz Azari, 2014, 82).

one of the basic variables in organizational behavior is job performance. Job performance means the degree to which employees perform jobs assigned to them in a certain working condition (Moheaddin and Suleiman, 2007) and are defined as general values for the organization of individual behavioral pieces that a person does during a given period of time (Nastizaei, 2014, 6378).

Teachers are the most important and influential factors in the school and are responsible for their job performance and student progress and targeted operations in the organization. Therefore, teachers have to be motivated to work motivated and motivated to gain job performance. Motivation will affect the effectiveness of the individual on the overall effectiveness of the school. The importance of the educational leadership and its role in school success and improvement is not covered in anyone. with regard to this, researchers and policy makers always believe that leadership is the main pillar of school reform and in order to explain and interpret the term that the training leadership is different from other leaders in other organizations (Yasini, 2013).

According to the discussion, I address the main question of the research as follows: Does the use of the curriculum affect teacher job performance? Secondary Questions:

1) Is the knowledge of the use of the classroom to affect the teacher 's job knowledge?

2) Is the proficiency of the teacher 's job expertise affect the teacher 's job skills?

3 ) Is the attitude of the classroom to affect the attitude and behavior of the teacher?

\section{Research goals:}

Overall purpose: examining the role of the curriculum on job performance of the secondary school teachers of Sari County. Partial goals:

1) Check the knowledge of the use of the curriculum on teacher job knowledge.

2) Check the proficiency of the teacher 's job skill in the teacher 's job skill.

3) Check the attitude of the classroom " s attitude on the attitude and behavior of the teacher. 


\section{Research hypotheses:}

The main hypothesis: there is a positive correlation between the teacher 's job plan and job performance. Secondary hypotheses: There is a positive correlation between the knowledge of the teacher 's job plan and job knowledge. There is a positive correlation between the skill of the teacher 's job design and job skill. There is a positive correlation between the attitude toward the classroom and the teacher 's attitude and behavior.

\section{Research variables:}

The lesson plan as an independent variable and job performance as the dependent variable is dependent on the variables of knowledge, skill and attitude.

\section{Theoretical basics and history of research:}

(Educational Design) is one of the major steps of activity in teaching and curriculum, and teachers have to devote much of their time to the design and sharing of textbooks and studying the various resources related to the subject of teaching and locating and exploiting their goals in the curriculum annually and in the curriculum. The training design comes after determining the educational goals and familiarity with cognitive, emotional, and mental areas that are of particular importance, Done(Khanifar,2007). As a result, all scholars in the educational system and curriculum agree that change in content and quality of educational programs, curricula and improving the process of teaching and learning requires the use of methods and techniques of teaching in particular (Niaz Azari, 2014, 81).

\section{Knowledge of Lesson Plan Design:}

Educational Design, as a dynamic process involving its constituent elements, is divided into four phases: analysis and setting of training targets; analysis and setting of training; analysis and determination of content, methodology, training, and assessment of the assessment system. appropriate targets on the quality of other structures such as content selection, method, means, and system are effective; the training methods also affect the fulfillment of goals. To ensure the appropriateness of the project, it should consider the effect of two or more factors on the plan and modify each of these factors when faced with the problem by analyzing each of those factors (Shabani, 2012; 241).

\section{Skill of Lesson Plan Design:}

A course of training may include a week, a month, a term or a school year. The curriculum regulator must divide the educational content of a period based on purpose, results, and time, into various phases and meetings. in order to achieve the goals set, programs and training activities have to be tailored to the ability of the learners and the time required in order to achieve a systematic and objective structure (i.e., 248).

A well - written curriculum enables the teacher to think regularly and systematically during the course of training, predicting all the effective factors in teaching, with detailed design of his training sessions and the effectiveness of the learning - learning process (i.e., 248).

\section{The attitude of Lesson Plan Design:}

It should be noted that the conducted study does not evaluate the effectiveness of the classroom in what the students have learned, but the criteria for applying the views of students. In any case, based on most of the analysis of educational activities, lack of education or lack of teaching 
design and teaching skills depends on the cultural background, educational purposes, students ' personality traits and rather than teacher behavior (Shabani, 2012; 163, 164).

\section{The teacher 's job performance:}

Teachers are the most important and influential factors in the school and are responsible for their job performance and student progress and targeted operations in the organization. Therefore, teachers have to be motivated to work motivated and motivated to gain job performance. Motivation will affect the effectiveness of the individual on the overall effectiveness of the school. The importance of the educational leadership and its role in school success and improvement is not covered in anyone. with regard to this, researchers and policy makers always believe that leadership is the main pillar of school reform and in order to explain and interpret the term that the training leadership is different from other leaders in other organizations (Yasini, 2013).

The following diagram shows the sub - sections of job performance:

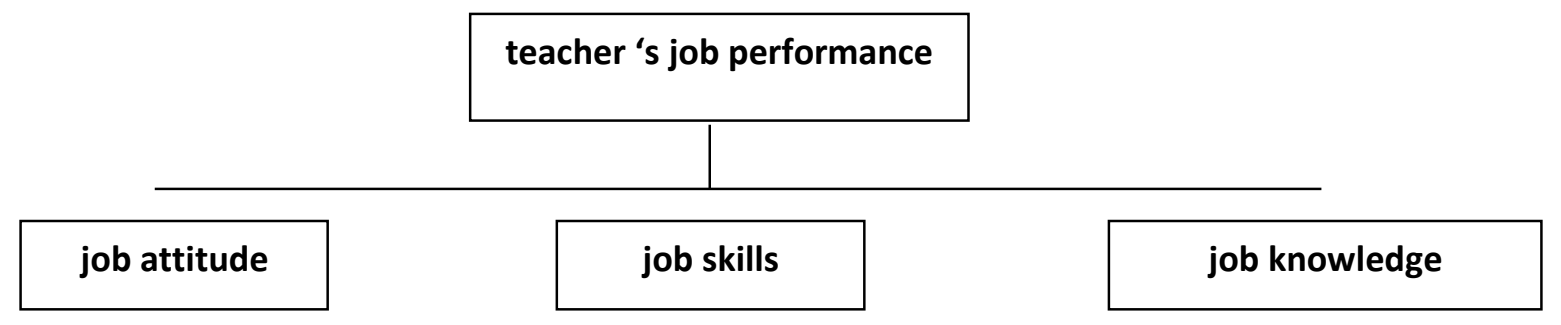

Diagram 1 - diagram of teacher 's job performance

\section{The teacher 's job knowledge:}

The teacher 's job knowledge is divided into two categories of specialized knowledge and public knowledge. Specialized knowledge or knowledge that defines the scientific and information skills that specify the field of teaching, and general knowledge that shows mastery in teaching methods or professional and professional skills, which represent the true policy of his career.

\section{The teacher 's job skills:}

UNESCO (2008) defines education as key to development of communities and the path that enables individuals to realize their abilities and enhance control on effective decisions. The UNESCO International Commission in Book (Education for the 21st Century) believes that learning throughout life and involvement in society is a key factor in responding to challenges of the world rapidly. The commission stresses four learning pillars - learning to learn, to learn to do, learn to live together and learn to grow. Today society has moved from compulsory education to focus on the quality of education, and the new reform of the curriculum emphasizes the development of education skills, how to learn, develop curricula and use various teaching strategies. Such changes involve a change in the role of the teacher (Lee et al., 2003). The teacher's role is changed from the transmitter of information with the help of the learning, the guide, and the correspondence with the student. This new role does not lessen the importance of teacher status but also requires knowledge acquisition and new skills (Shah Mohammadi, 2014).

\section{Classroom Management:}

Class, as a social system, is a place to educate and train. Students as a social group have common beliefs, norms, and values so that they are called a (small community). Educational activities will 
lose its effectiveness and efficiency if it does not address the attributes, wants, needs and beliefs of the social group in the education - learning process.

classroom management, as well as managing other social situations, requires skill in functions such as design, organizing, leadership, monitoring, control, and assessment. According to these functions and its proper implementation, the classroom and the educational environment will contribute to effective and enjoyable students (Shabani, 2012: 141). The human force includes managers, teachers, students and their parents are the main factors in planning educational environments that can play a more valuable role than physical and economic resources in the educational activities process. Undoubtedly, the most effective force in the classroom than the other human resources is the teacher whose insight and knowledge regarding classroom management and organizing educational activities can lead to the development of school system functions, make the school environment attractive and exciting for students. (i.e.; 143)

\section{The teacher's job attitude:}

One of the most important factors on performance can be referred to individual behavior, motivation, positive reinforcement, vision, competence and leadership in organization, organization, organizational relationships and decision - making, organization structure, organizational relationships and decision - making, learning and training, organizational change and improvement (Fattah et al., 2011), all of which can include the quality of work life (Nastizaei, 2013; 63-78).

\section{Teacher:}

A well - informed teacher must be able to use the best - to - date methods in the classroom because he is the most important element of classroom and personality affecting the students. The success or failure of each student directly relates to the type of teacher behavior and his ability, because awareness of the conditions of the class and the environment in which the teacher teaches is very important in the effectiveness of classroom behavior. The successful teacher must know the status of the class by knowing the issues and steps of individual development, and adjust their behaviors to the needs and demands of the students and conditions in mind (Farajollahi, 2014, 44 - 45).

\section{Intermediate Period:}

The intermediate period of psychology is a period in which the maximum compromise between individual traits and educational requirements is possible, from the social aspect of education that students become independent and responsible for future life and ultimately seek to prepare young people for future responsibilities and gain income through learning a set of organized information and a variety of job skills (i.e.).

\section{Research background:}

Azade Mohammadi (2015) from the teacher's perspective, effectiveness of teaching technologies is effective on improving the learning - learning process and quality of teaching, and its application in lessons class leads to motivation in teacher and learning process learning, optimal communication, better evaluation of learning - learning process, teacher - learning, teaching. Abdollah Khalife (2015) In Properties showed an effective and efficient language teacher from the students ' point of view; the students critically assessed the four sets of features: knowledge and skill of the English language, knowledge of education and teaching, organizing skills and communication, and social - emotional traits. Considering that both classes of knowledge class and English language skills are of paramount importance. It can be concluded, however, that the 
views of the college students and the school 's students are no different in general, although there are minor differences in the opinions of the two groups. in addition, there was no.

Somaye Akbari (2014) in examining the relationship between organizational learning with the quality of teaching of secondary school teachers in the school year 2013 - 14, there is a significant relationship between organizational learning with the quality of teaching teachers of "Bandar Abbas" secondary schools. the results of the study showed that all aspects of organizational learning are significantly related to teacher teaching quality. also, the regression results showed that among the nine of the nine variables entered into the model of culture of organizational learning, teamwork, knowledge sharing, participation development, employee competency development were significantly and significantly able to predict the quality of teaching of secondary school teachers of Bandar Abbas. the results of the independent t test show that there is a difference between secondary schools for girls and boys in Bandar Abbas in terms of organizational learning. the results showed that there is no significant difference between secondary schools for girls and boys in Bandar Abbas in terms of organizational learning.

Fatemeh Gholamzadeh (2014) at the role of teachers ' curriculum on the quality of teaching and the academic vitality of the fifth and sixth grade of the city, the curriculum orientation of teachers is related to the quality of teaching them. Also, the results of the stepwise regression test showed that the student 's academic vitality, in terms of their teachers ' curriculum orientation, only eclectic approach can be a predictor of students ' academic vitality. The stepwise regression results show that the quality of teaching quality only after teaching can be a predictor of students ' learning vitality. moreover, the results of multivariate analysis showed that the orientation of teachers ' curricula is not different in terms of their work history and their gender.

Jalalat Parmeh (2014) in the study of the relationship between teacher creativity and the quality of teaching with emphasis on "Piranshahr" interaction system flanders in Piranshahr city secondary and secondary school, there is no meaningful relation between teacher creativity with direct teaching methods, indirect teaching method and student participation. also, among the flanders factors, the only factor in ambiguity and silence with creativity has a significant relationship.

Hesam Azari (2013) The effect of training courses on Iranian teachers ' beliefs: a step towards an effective training course; teacher training courses have the ability to change teachers ' beliefs. They were able to make the most of the change in the same context in teachers ' beliefs, as they devoted a significant portion of the research to practical teaching issues. on the other hand, because the beliefs of teachers prior to the course were also closely related to the teachers ' beliefs, there was no significant statistical influence on teachers ' beliefs in this regard.

\section{Research Methodology:}

This research is applied and descriptive - correlation. the correlation between variables is analyzed based on the purpose of the research. the present study is the correlation type and regression analysis. In most studies, the correlation coefficient is used by default of two variables for measuring the variables, so the correlation coefficient calculated in this type of research is the Pearson product - moment correlation coefficient or, in short, the Pearson correlation coefficient. to explain the correlation of variables, we used the linear - regression analysis test. This test predicts the dependent variable using one or more independent variables, which uses a linear model for this purpose.

in order to find the significance of the statistics calculated in the regression equation, the tests were used as a meaningful test of $\mathrm{R}^{\wedge} 2$. for the elegance of the model, the test is performed with the test F. finally, in order to explain the relationship between variables, the coefficient of regression 
coefficients $\left(b_{-} i\right)$ in which the ratio of the desired coefficient on the standard deviation of that statistic is that of distribution $t$ (Sarmad, Bazargan, Hegazi, 2015; 229-230).

The statistical community of research:

the population of the study consists of all secondary teachers of Sari to It amounts to 1059 people. sampling method and sample size:

The sample size for this study was determined using the formula of Cochran 280 people, which using stratified random sampling of each class consisted of male and female teachers in sari city of 100 and 180 people, respectively.

Job Performance questionnaire:

The Job Performance questionnaire used in this study has three sub - categories as follows:

1 - Job knowledge of a teacher (questions 1 through 6)

2 - Job skills of a teacher (questions 7 - 14)

3 - attitude toward teacher job (questioning 15 to 25)

scoring method: The questionnaire was prepared and calibrated based on a Likert scale ranging from 0 to 4 scores on the spectrum and scores between zero to 4:

$\begin{array}{ccccc}\text { Very High } & \text { High } & \text { mean } & \text { little } & \text { very little } \\ 4 & 3 & 2 & 1 & 0\end{array}$

\section{Data Analysis Methods:}

in order to analyze the data, SPSS software was used in two parts descriptive statistics and inferential statistics. to describe the statistical sample and raw data from the research variables, descriptive indexes such as frequency distribution, mean, median, standard deviation, variance and standard error were used and data analysis was used to analyze the data from the inference methods such as univariate correlations and linear regression test.

\section{Research findings:}

Description of the variables of the research:

the research variables include job performance variables and sub measuring instrument (teacher job knowledge, teacher job skills and attitude toward teacher job) and the curriculum and under scale (knowledge plan), we describe.

Table 1 - descriptive statistics of research

\begin{tabular}{|c|c|c|c|c|c|c|c|}
\hline $\begin{array}{c}\text { Research } \\
\text { variables }\end{array}$ & $\begin{array}{c}\text { numbe } \\
\mathbf{r}\end{array}$ & $\begin{array}{c}\text { averag } \\
\mathbf{e}\end{array}$ & $\begin{array}{c}\text { norm } \\
\text { al }\end{array}$ & $\begin{array}{c}\text { standard } \\
\text { deviation }\end{array}$ & variance & $\begin{array}{c}\text { minimu } \\
\text { m }\end{array}$ & maximum \\
\hline Job performance & 280 & $75 / 34$ & 74 & $10 / 52$ & $110 / 74$ & 42 & 96 \\
\hline job knowledge & 280 & $21 / 45$ & 21 & $3 / 81$ & $14 / 53$ & 13 & 28 \\
\hline Job skills & 280 & $21 / 05$ & 21 & $3 / 14$ & $9 / 86$ & 12 & 28 \\
\hline job attitude & 280 & $32 / 90$ & 33 & $5 / 39$ & $29 / 15$ & 16 & 44 \\
\hline Lesson Plan & 280 & $66 / 14$ & 67 & $13 / 50$ & $182 / 33$ & 30 & 99 \\
\hline $\begin{array}{c}\text { knowledge of } \\
\text { Lesson Plan }\end{array}$ & 280 & $18 / 12$ & 19 & $4 / 42$ & $19 / 54$ & 7 & 28 \\
\hline $\begin{array}{c}\text { Skill of Lesson } \\
\text { Plan }\end{array}$ & 280 & $18 / 52$ & 18 & $3 / 75$ & $14 / 05$ & 7 & 28 \\
\hline $\begin{array}{c}\text { The attitude of } \\
\text { Lesson Plan }\end{array}$ & 280 & $29 / 49$ & 31 & $54 / 6$ & $42 / 80$ & 7 & 44 \\
\hline
\end{tabular}

The results of Table 1 indicate that: 
- The job performance variable has an average of 75 / 34 with a standard deviation of $10 / 52$. this indicates that the average job performance is at a good level. as well as Job knowledge with an average of 21 / 45 with a standard deviation of 3 / 81, teacher job skill with an average of 21 / 05 with a standard deviation of $3 / 14$ and the attitude toward a teacher job has an average of 32/90 with a standard deviation of $5 / 39$.

- the study variable has an average of $66 / 14$ with a standard deviation of $13 / 50$. this indicates that the average subject of the subject is on average (close to good). Also The course of the course plan has an average 18 / 12 standard deviation with a standard deviation of 4 / 42, the skill to write the course with an average of 18 / 52 with a standard deviation of 3/75 and the attitude towards the teaching scheme has an average of 29/49 with a standard deviation of 54/6.

\section{Normality test (kolmogorov - smirnov):}

the Kolmogorov - Smirnov test was used to investigate the normality of the data distribution, with the results presented in Table 2.

H0: the data follows a normal distribution.

H1: the data does not follow a normal distribution.

Table 2- normality analysis of data distribution

\begin{tabular}{|c|c|c|}
\hline Research variables & Sample Volume & meaningful level \\
\hline Job performance & \multirow{8}{*}{280} & $0 / 081$ \\
\hline job knowledge & & $0 / 208$ \\
\hline Job skills & & $0 / 092$ \\
\hline job attitude & & $0 / 100$ \\
\hline Lesson Plan & & $0 / 074$ \\
\hline knowledge of Lesson Plan & & $0 / 164$ \\
\hline Skill of Lesson Plan & & $0 / 092$ \\
\hline The attitude of Lesson Plan & & $0 / 103$ \\
\hline
\end{tabular}

according to table 2 , because of $95 \%$ confidence level and $\alpha=0.05 \mathrm{~s}$, significant level is calculated for all variables Sig $>0 / 05$, so the null hypothesis is rejected and the hypothesis of the study is rejected. therefore, the data is followed by normal distribution and for the deductive analysis of data, the use of parametric statistical tests is allowed.

studying the questions of the research:

to investigate the research questions, the Pearson correlation coefficient and the regression analysis were used and the results are summarized in the following table: 
Table 3 - Results of the regression analysis and regression analysis

\begin{tabular}{|c|c|c|c|c|c|c|}
\hline Variables & $\begin{array}{c}\text { correlation } \\
\text { coefficient } \\
(\mathbf{R}) \\
\end{array}$ & $\begin{array}{c}R^{\wedge} 2 \\
\text { modified }\end{array}$ & $\begin{array}{c}\text { The } \\
\text { value of } \\
\text { the } f \\
\end{array}$ & $\begin{array}{l}\text { meaningful } \\
\text { level }\end{array}$ & $\begin{array}{c}\text { Beta } \\
\text { standard } \\
\text { coefficient }\end{array}$ & $\begin{array}{c}\text { meaningful } \\
\text { level }\end{array}$ \\
\hline $\begin{array}{l}\text { Lesson Plan } \\
\text { Job } \\
\text { performance }\end{array}$ & 0.738 & 0.543 & 332.710 & 0.000 & 0.738 & 0.000 \\
\hline $\begin{array}{c}\text { knowledge } \\
\text { of Lesson } \\
\text { Plan } \\
\text { job } \\
\text { knowledge }\end{array}$ & 0.546 & 0.295 & 117.98 & 0.000 & 0.546 & 0.000 \\
\hline $\begin{array}{c}\text { Skill of } \\
\text { Lesson Plan } \\
\text { Job skills }\end{array}$ & 0.669 & 0.445 & 224.739 & 0.000 & 0.669 & 0.000 \\
\hline $\begin{array}{l}\text { The attitude } \\
\text { of Lesson } \\
\text { Plan } \\
\text { job attitude }\end{array}$ & 0.571 & 0.323 & 134.77 & 0.000 & 0.751 & 0.000 \\
\hline
\end{tabular}

\section{Discussion and conclusion:}

For the main question of the study, the correlation coefficient between the variables in the model is $0 / 738$ and the modified determination coefficient is $0 / 543$. This result indicates that around 54 $\%$ of the variation of the variables is explained by the linear regression model. the mean value of statistic $\mathrm{f}(000)$ is less than the allowable limits (0.05). therefore, the elegance of the model is approved. The result shows that there is a regression relation between the changes in the teacher job performance variable using the regression study. Therefore, the null hypothesis that the study does not affect the teacher job performance is rejected and the research hypothesis is accepted.

also, the constant value of the regression model is 37/295. The standardized beta coefficient for the use of the lesson design is $0 / 738$. Therefore, the influence of the variable on the teacher 's job performance is approximately $74 \%$.

It can be said that from the teachers ' point of view, a good lesson plan has been set which addresses the minimum elements and structures such as the subject of the curriculum, outlines of literature, general purpose, partial and behavioral goals, etc., can affect their job performance. On the other hand, as Farraj Allahi said that each teacher had to work for every lesson and curriculum to be prepared in order to achieve educational goals in the classroom, so the hypothesis could match the words of Farraj Allahi but the hypothesis and the teachers ' point of view are in conflict with what said, Shabani says, teachers should not insist on the implementation of their planned programs and forget the creativity and participation of students in the educational situation.

For the first sub - question of the study, the correlation between the variables in the model is 0/546, The modified finding coefficient is 0 /298. this result indicates that around 30 percent of the changes of the variables are explained through the linear regression model. 
on the other hand, the significance level of statistic $\mathrm{f}(000)$ is Less than allowable limits (0.05) have been. therefore, the elegance of the model is approved. the result indicates that there is a regression relation between changes in teacher job knowledge with knowledge of the study. Therefore, the null hypothesis that knowledge of the classroom does not affect the teacher 's job knowledge is rejected and the research hypothesis is accepted. also the constant value of the regression model is $12 / 919$. he standard beta coefficient for the knowledge variable is $0 / 546$. Therefore, the influence of the student 's variable on the use of the classroom in the teacher 's job knowledge is approximately $55 \%$.

Therefore, one teacher can say that a teacher can be more effective in transferring concepts if he knows how to use the It has been drawn up, which requires that each teacher has sufficient knowledge about his job.

For the second sub - question; correlation coefficient between variables in the model is 0/669, The modified finding coefficient is $0 / 445$. This result indicates that around $45 \%$ of the variation of the variables is explained by the linear regression model. on the other hand, the significance level of statistic $\mathrm{f}(000)$ is Less than allowable limits (0.05) have been. therefore, the elegance of the model is approved. the result indicates that there is a regression relation between the changes in the teacher job skill variable with the skill of the regression relationship. Therefore, the null hypothesis that the skill does not affect the teacher job performance is rejected and the research hypothesis is accepted. also, the constant value of the regression model is 10 / 675. the standard beta coefficient for the skill variable of the study is $0 / 669$. therefore, the influence of the skill variable using the lessons in teacher job skills is approximately 67 percent.

Therefore, since the lesson plan should be set in such a way that even a novice can perform its educational activities in the classroom, it can be said that if the teacher does not have enough skill to use the curriculum, it will improve its performance, and that requires sufficient skill in the job. And according to what was stated in the second chapter, the professional teacher should enjoy content knowledge, child and adolescent development, learning styles, teaching strategies, and a new set of values associated with respect for individual differences, co - operation with colleagues and ....

for the third sub - question of the research; correlation coefficient between variables in the model is $0 / 571$, The modified finding coefficient is $0 / 323$. This result indicates that around $32 \%$ of the variation of the variables is explained by the linear regression model. on the other hand, the significance level of statistic f (000) is Less than allowable limits (0.05) have been. therefore, the elegance of the model is approved. the results show that there is a regression relation between changes of attitude and teacher behavior with the attitude of using the course of the study. Therefore, the null hypothesis that the attitude of the study does not affect the attitude and behavior of the teacher is rejected and the research hypothesis is accepted. also, the constant value of the regression model is 19 / 006. the standard beta coefficient for the attitude variable is the application of the lesson plan to 0/571. therefore, the influence variable on the attitude of the subject in attitude and behavior of the teacher is approximately 57 percent.

As a result, as one of the most important factors affecting performance can be referred to as input behavior, motivation, positive reinforcement, redesign, morale, strength and leadership in the organization and ..., therefore, the view of the teacher is directly affecting the attitude of the teacher and the behavior of the teacher and ultimately on learning the student.

\section{Research limitations:}


1- This study includes only secondary school teachers in Sari County (one and two), so the generalizability of the results to other teachers in other cities should be cautious.

2- Lack of internal research on the subject of the classroom, as well as its relation to the job of a teacher.

3- Financial constraints, the time and lack of cooperation of some teachers in response to the questionnaire.

\section{Research proposals:}

1) Future research is suggested that the relationship between the work plan and job performance using pretest and posttest are being studied from groups of stakeholders.

2) Future research suggests that intervention factors such as gender, degree of education and work history are investigated as research variables.

3) It is suggested that further research is conducted in this field because there is very little research in the field of teaching and its relationship with effective factors on learning students.

\section{Applied recommendations:}

1) Education professionals such as teachers, training experts and ... can benefit from the results of this research and work in their role to perform better learning - learning.

2) By holding periods of service, training workshops and conventions associated with the curriculum and its relationship with job performance in job promotion and professional qualifications of teachers.

3) The allocation of incentives such as the promotion of rank, certification of prestigious certificates, and its impact on teacher " $\mathrm{s}$ annual scores using a classroom for annual assessment and organizing teachers and teachers can be effective in enhancing the attitude toward the classroom.

\section{Resources:}

Akbari, somayye. (2014). examining the relationship between organizational learning with the quality of teaching of bandarabbas secondary school teachers in the school year $2013-14 \ldots$ government, research, and technology - the university of shahid bahonar.

Azari, Hossam. (2013). The impact of teacher training courses on Iranian teachers ' beliefs: a step towards an efficient teacher training course ... the Ministry of Science, Research, and Technology - University of tabatabaei, University of Literature.

Faraj allahi, Mehran. talebi, saeid. (2014). The curriculum in the secondary school. payam nor Press and Publication Center.

Gholamzadeh, Fatima (2014). the role of the teacher's curriculum on the quality of teaching and the academic vitality of the first and sixth grade of the city was defined. University of Sciences, Research, and Technology - birjand University, master " s master " s.

Khalifa, Abdullah. (2015). The characteristics of an effective and efficient language teacher from the student point of view. Non - governmental - Islamic Azad University - Islamic Azad University of marvdasht - Faculty of Educational and Psychology, master " s master " s.

Mohammadi, azadeh. (2015). The teachers ' perspectives on the effectiveness of employing educational technologies to improve the process of teaching - learning and quality of teaching. Department of Science, Research, and Technology - Semnan University - Faculty of Psychology and Education master " s master" s. 
Nastizaei, Nasser. (2014). prediction of job performance of teachers is based on Walton work quality model. Innovation Management Innovation. Year 10. The number 1(serial 37). Winter.

Niazazari, kiomars(2014). check the factors influencing the willingness to adjust the course of teaching in the teaching process. Research journal in the curriculum. eleventh year. Second period. Number 15.

Parme, jalalat. (2014). relationship between teacher creativity and their quality of teaching with emphasis on flanders analysis system in piranshahr city secondary and secondary school, Department of Science, Research, and Technology - The University of Tabriz, Faculty of Psychology and Education. master "s master " s.

Sarmad, Zohra. bazargan, Abbas. Hegazi, elahe. (2015). Research methods in behavioral sciences. agah Publishing. Tehran.

shabani, Hassan. (2012). Teaching and education skills: First volume (Methods and techniques of teaching). samt Publishing. Tehran.

Shahmohammadi, Nayere. (1393). primary education development. Period of the eighteenth. No. 1.

Yasini, Ali. (2012). The role of the distributional leadership style of managers on job performance of the mehran school teachers: providing a model. Research Science Quarterly, a new approach to teaching management Azad Eslami Unit Marvdasht University. Fourth year number 1 spring 